\title{
Cleaning of Graphite Particles Embedded in the Surface of Ductile Iron by Using a Novel Method
}

\author{
Baoshen Jia, Xinxiang Miao, Yilan Jiang, Hongping Tang, and Caizhen Yao
}

Laser Fusion Research Center, Chinese Academy of Engineering Physics, Mianyang 621900, China

Correspondence should be addressed to Caizhen Yao; yaocaizhen2008@126.com

Received 27 October 2020; Revised 17 December 2020; Accepted 6 January 2021; Published 20 January 2021

Academic Editor: Bowen Guan

Copyright (c) 2021 Baoshen Jia et al. This is an open access article distributed under the Creative Commons Attribution License, which permits unrestricted use, distribution, and reproduction in any medium, provided the original work is properly cited.

\begin{abstract}
Ductile iron has unique mechanical property and has been widely used in many industrial applications, e.g., engine cylinder covers, crank axles, and machine tool beds and cams. The welding performance of ductile iron is normally influenced by graphite particles in the surface of ductile iron, which needs to be removed before welding. In this article, laser cleaning technique was developed to remove graphite particles implanted in the surface of ductile iron. Laser cleaning parameters and the damage threshold value of the substrate were investigated by using a pulsed Nd: YAG laser. The optimized laser cleaning parameters were obtained to achieve high-quality cleaning effect and avoid the formation of the oxide layer. Surface morphologies and elemental compositions of specimens before and after laser cleaning were characterized by scanning electron microscopy and energydispersive X-ray spectroscopy. Results indicated that graphite particles implanted in the surface of ductile iron were removed completely and efficiently by using the pulsed laser without the protection of inert gas atmosphere, and surface oxidation was not observed during the laser cleaning process.
\end{abstract}

\section{Introduction}

Ductile cast iron is used extensively in different industrial fields for the manufacturing of engine cylinder covers, crank axles, machine tool beds and cams, and so on. It is a potential replacement of steel in some applications due to its excellent casting performance, extraordinary abrasive resistance, outstanding corrosion resistance, and the well combination of toughness and strength [1-4]. Phase compositions of ductile cast iron are pearlite, ferrite, and graphite phases, with ferrite as the matrix. However, graphite particles implanted in the surface of ductile iron could affect the quality of coating, reduce the welding performance, and short the service life of the workpiece. Those particles need to be removed completely before welding [5]. Techniques have been developed by researchers to remove graphite particles, in which the sand-blasting method is the most commonly used. Sand blasting [6] is an efficient and effective technique for the cleaning of the large surface area. However, it is time and energy consuming for the cleaning of small workparts of ductile iron. Chemical etching [7] is not suitable for the removal of graphite particles due to their chemical stability. Recently, laser cleaning technique has been developed as a novel method to remove surface contaminants [8-11]. Comparing with traditional surface treatment techniques, laser cleaning is environmentally friendly for direct removal of contaminants without altering or affecting properties of matrix.

Different from continuous lasers for cutting, welding, and cladding, pulsed laser source was employed for laser cleaning. Laser cleaning is a multifactor process with mechanism of evaporation, ablation, acoustic effect, and impact effect (Figure 1) [12]. Intensity and spatiotemporal characteristics of radiation play the main role during laser cleaning process. Cleaning effect is also related to the absorbing ability of the material, which strongly depends on temperature, thermal conductivity, and other factors.

When laser irradiates on metal surface, the metal partially absorbs the laser radiation, and it will be heated, melted, partially evaporated, and ionized. A rigorous mathematical description of the interaction taking into account all participating physical processes is complex. 


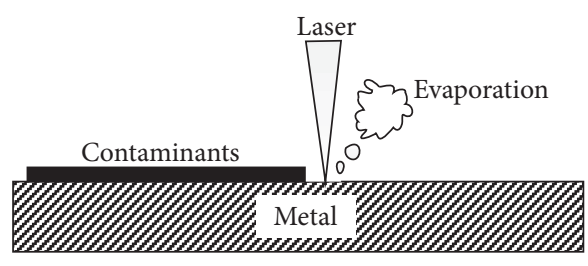

(a)

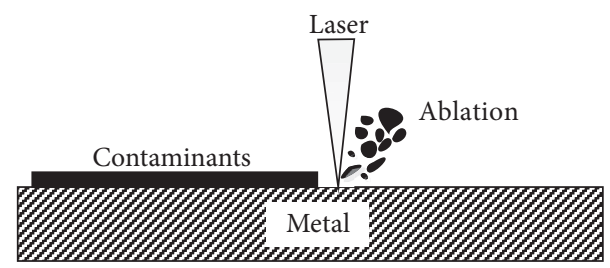

(b)

FIgURE 1: Mechanism of destruction of contaminants on metal's surface: (a) evaporation and (b) impact ablation [12].

Depending on the power density of the radiation impacting the surface, laser cleaning can be implemented by evaporation process, impact process, or acoustic and thermoplastic forces $[12,13]$. Evaluations indicate that effective cleaning due to evaporation for most materials (Figure 1(a)) is achieved at the power density of $10^{7}-10^{8} \mathrm{~W} / \mathrm{cm}^{2}$. A low threshold thermal-chemical impact ablation mechanism of the film can be implemented under the effect of pulsed laser radiation with power density lower than $10^{7} \mathrm{~W} / \mathrm{cm}^{2}[12,14]$ (Figure 1(b)). Laser cleaning technique has been successfully applied to removal of paint and oxide layer on metal surfaces, cleaning of optical and electronic elements, and conservation of cultural heritage [15-22]. However, few research studies have been carried out on laser cleaning of ductile iron.

Inspired by the effectiveness of the laser cleaning technique for the removal of surface contaminants, in this work, the infrared high-repetition nanosecond pulsed laser was employed to remove graphite particles implanted in the surface of ductile iron. The technical details of laser cleaning and removal possibilities of graphite particles with different implantation forms were discussed. Cleaning effects of different laser parameters were investigated. Surfaces before and after laser treatments were characterized by scanning electron microscopy (SEM) and energy-dispersive X-ray spectroscopy (EDS). The optimized cleaning parameters and the damage threshold value of the substrate were obtained. Results indicated that laser cleaning is an effective and environmentally friendly technique for the removal of graphite particles, which will not lead to degradation of essential performance of the ferrite matrix.

\section{Materials and Methods}

2.1. Sample Preparation. Different from the contaminants adhered to the surface of substrate, for ductile iron, graphite particles are embedded in the ferrite matrix, and it is technically more difficult to be removed. The cleaning process and laser parameters are different from those for cleaning of the dusts, rubber particles, and paints from the substrate. If the shape of graphite particles is assumed as a regular sphere, the implanted particles have 4 forms in the iron substrate as shown in Figure 2.

It is obvious that shallowly embedded particles can be removed easily. Particles A and B in Figure 2 can be removed by laser ablation. However, for particle $C$, evaporation should be the main mechanism. A few particles like $D$, because of their small exposed area, are difficult to be removed completely by laser cleaning or sand blasting. Furthermore, it is difficult to calculate the adhere force between graphite particles and matrix, which is necessary to decide laser parameters when ablation is the main mechanism in a cleaning process. In this case, evaporation mechanism is more suitable for ductile iron cleaning. The boiling point of graphite is higher than that of iron, and it is much higher than melting point of iron; therefore, iron substrate would melt and gasify during laser cleaning process. Melting and gasification of iron substrate are acceptable phenomenon. If a power intensity higher than $10^{8} \mathrm{~W} / \mathrm{cm}^{2}$ is used during laser cleaning process, oxidation may be induced, which is not acceptable for further treatment of iron substrate. Iron oxide will be formed quickly in atmosphere when the temperature is higher than $5000^{\circ} \mathrm{C}$.

In this work, a ductile iron club was chosen as the research target, and it was cut into small specimens with a dimension of $\phi 20 \mathrm{~mm} \times 8 \mathrm{~mm}$. Specimens were cleaned by using alcohol to remove particulate and organic contaminants from the surface.

2.2. Experimental Setup. The schematic diagram of the laser cleaning system is shown in Figure 3. Specimens were fixed on a platform moving along $Y$-axis controlled by a computer. Laser beam movement on surfaces of specimens was controlled by a directional control system in $X$-axis, and its movement in $Y$-axis was achieved by the movable platform. High power densities were guaranteed by an F- $\theta$ lens, which focused the laser beam on the surface of specimen with a spot diameter of $500 \mu \mathrm{m}$ at focal plane. Values of fluence were adjusted by varying the output power while keeping the repetition rate and pulse duration the same. To obtain the threshold fluence, several fluence values were chosen to determine the optimal condition for the graphite removal. Surfaces were cleaned several times to remove the implanted graphite particles completely. Inert gas was not applied to the irradiated area during the laser cleaning process.

A Q-switched Nd:YAG laser system with a maximum power of $400 \mathrm{~W}$, repetition rate of $5-100 \mathrm{kHz}$, and pulse duration of 60-100 ns was employed in laser cleaning experiments. The diameter of laser spot at focal plane was $500 \mu \mathrm{m}$. During the experiment, the repetition rate of the laser was much higher than the scanning rate, ensuring the complete surface coverage during cleaning process. Meanwhile, the scanning rate was matched to the repetition rate, ensuring a small overlap rate (20\%) to reduce the influence of energy accumulation. 


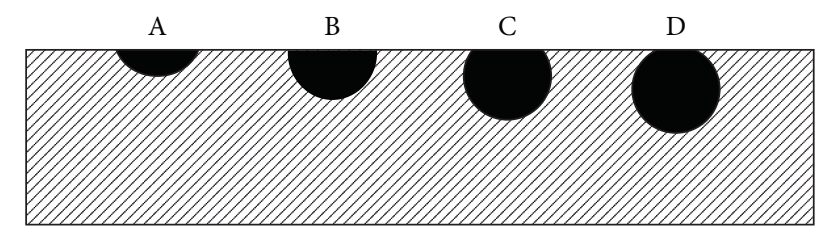

Figure 2: Schematic diagram of graphite particles embedded in the ferrite substrate.

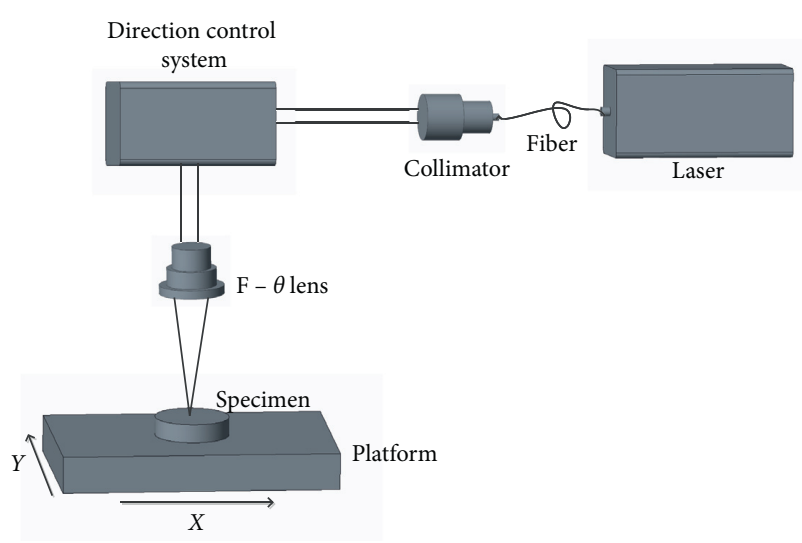

FIgURE 3: Schematic diagram of the laser cleaning setup.

\section{Results and Discussion}

3.1. Theoretical Calculation. Considering that the radiation is absorbed in the near-surface metal layer, while parameters such as diffusivity $\alpha_{t}$ and thermal conductivity $\mathrm{K}$ are constant, the heat conduction equation can be written as follows [12]:

$$
T(z, t)=T_{0}+\frac{2 P(1-R)}{K S}\left\{\sqrt{\alpha_{t} t} * \operatorname{ierfc}\left(\frac{z}{2 \sqrt{\alpha_{t} t}}\right)\right\},
$$

where $T(z, t)$ is the temperature of the material at depth $z$ after time $t, P$ is the power of a single pulse, $S$ is the area of spot, $T_{0}$ is room temperature, $R$ is reflection of ductile iron, and ierfc () is the error function. The value of ierfc () varies with values of depth $z$ and time $t$. Critical density of the radiation flux to attain the boiling point on the surface of the material can be determined by the temperature field. Critical temperature of $\mathrm{Fe}$ substrate can be obtained by using equation (1), and calculated results are shown in Figure 4. Thermal parameters of substrate are given in Table 1 .

Because inert gas is not applied, cleaning parameters especially oxidation threshold of laser power intensity should be obtained and optimized. According to the calculated results in Figure 4, oxidation threshold of laser power intensity is about $10 \mathrm{~J} / \mathrm{cm}^{2}$.

3.2. Experimental Demonstration. According to equation (1), a high temperature is needed to completely remove graphite particles. Thus, a high laser power intensity is required. There are two routes to increase the power intensity, one is to increase the output laser power and the other is to decrease the spot area. Increasing output power is much easier in comparison with decreasing the spot area. In this research, the average power was increased while maintaining other experimental parameters the same as shown in Table 2. The repetition rate was $15 \mathrm{kHz}$, the pulse duration was $100 \mathrm{~ns}$, and the scanning velocity was $3200 \mathrm{~mm} / \mathrm{s}$. The surface of the specimen was placed at the focal plane of the laser beam. The cleaning passes were carefully chosen. Cleaned specimens were judged by their appearance first and then evaluated by the combination of SEM and EDS analysis.

Based on previous analysis and the conclusion of reference [14], initial testing experiment on S0 is performed with a laser radiation power density of $6.79 \times 10^{7} \mathrm{~W} / \mathrm{cm}^{2}$ $\left(6.79 \mathrm{~J} / \mathrm{cm}^{2}\right)$. As shown in Figure 5, region A is the surface before cleaning and region $\mathrm{B}$ is the surface after cleaning. The color of cleaned surface is silver white, much brighter than that of original surface, and is approaching to the color of iron. It seems that the expected appearance has been achieved by only one-step laser cleaning.

Figure 6 shows detailed views of surface morphologies of initial (Figure 6(a)) and laser cleaned (Figure 6(b)) specimens. As previously mentioned, different from particulate contaminants adhere to the surface, Figure 6(a) shows that graphite particles (black area, e.g., C) with diameters ranging from $10 \mu \mathrm{m}$ to $50 \mu \mathrm{m}$ embedded in the matrix of ductile iron (gray area, e.g., D). Figure 6(b) indicates that graphite particles with diameters less than $10 \mu \mathrm{m}$ were completely removed (e.g., site 1), leaving implanted holes. Deeply embedded particles with diameters between 10 50 $\mu$ m were not completely removed (e.g., site 3). Shallowly implanted large particles were also completely removed (e.g., site 2). Comparing with Figure 6(a), it can be seen that the ferrite matrix melted due to the high laser radiation power density, which is in agreement with our previous analysis. In this case, evaporation is the main mechanism for ductile iron cleaning. The boiling point of graphite $\left(4830^{\circ} \mathrm{C}\right)$ is higher than that of iron $\left(2750^{\circ} \mathrm{C}\right)$, and it is much higher than melting point of iron $\left(1535^{\circ} \mathrm{C}\right)$; therefore, iron substrate melt and be gasified during laser cleaning process. Melting and gasification of iron substrate are acceptable for further welding treatment of ductile iron.

EDS analysis was employed for further investigation of the oxidation process during laser cleaning. Figure 7 shows the EDS results of regions $\mathrm{C}$ and $\mathrm{D}$ of initial specimen (Figure 6(a)) and region $\mathrm{E}$ of the cleaned specimen (Figure 6(b)). It can be seen from Figure 7(a) that the main elements of region $\mathrm{C}$ (graphite particle) and D (ductile iron substrate) are carbon and iron, respectively, which are consistent with the composition of ductile iron. Comparing with Figure 7(a), Figure 7(b) shows that the composition of iron substrate after laser cleaning is similar to that of the initial status, which demonstrates that oxidation does not occur on iron substrate during laser cleaning process. The result indicates that laser cleaning is a promising method to remove graphite particles implanted in ductile iron while preserving the mechanical property of the substrate. 


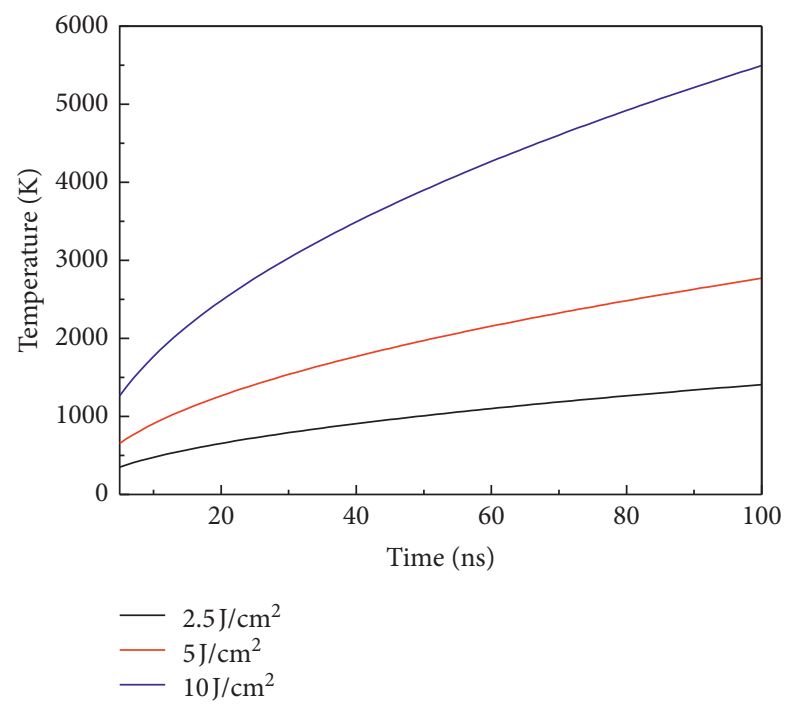

FIGURE 4: Time-temperature curves of the top surface at different energy intensities.

Table 1: Thermal parameters of Fe substrate.

\begin{tabular}{|c|c|c|c|c|}
\hline Thermal properties & Thermal conductivity $\left(W \cdot m^{-1} \cdot K^{-1}\right)$ & Density $\left(\mathrm{kg} \cdot \mathrm{m}^{-3}\right)$ & Specific heat $\left(J \cdot \mathrm{kg}^{-1} \cdot K^{-1}\right)$ & Absorptivity \\
\hline Fe substrate & 55 & $7.86 \times 10^{3}$ & $0.60 \times 10^{3}$ & 0.18 \\
\hline
\end{tabular}

TABLE 2: Designed laser cleaning parameters.

\begin{tabular}{lccccc}
\hline Nominated name & Power $(\mathrm{W})$ & Repetition rate $(\mathrm{kHz})$ & Diameter of spot $(\mathrm{mm})$ & Scanning rate $\left(\mathrm{mms}^{-1}\right)$ & Pulse duration $(\mathrm{ns})^{\text {Pass }}$ \\
\hline S0 & 200 & 15 & 0.5 & 3200 & 100 \\
S1 & 220 & 15 & 0.5 & 3200 & 1 \\
S2 & 240 & 15 & 0.5 & 3200 & 100 \\
S3 & 260 & 15 & 0.5 & 3200 & 100 \\
S4 & 280 & 15 & 0.5 & 3200 & 100 \\
S5 & 290 & 15 & 0.5 & 3200 & 100 \\
S6 & 290 & 15 & 0.5 & 3200 & 1 \\
S7 & 290 & 15 & 0.5 & 3200 & 1 \\
S8 & 300 & 15 & 0.5 & 3200 & 100 \\
S9 & 320 & 15 & 0.5 & 3200 & 100 \\
S10 & 320 & 15 & 0.5 & 3200 & 100 \\
S11 & 340 & & & 100 & 1 \\
\end{tabular}

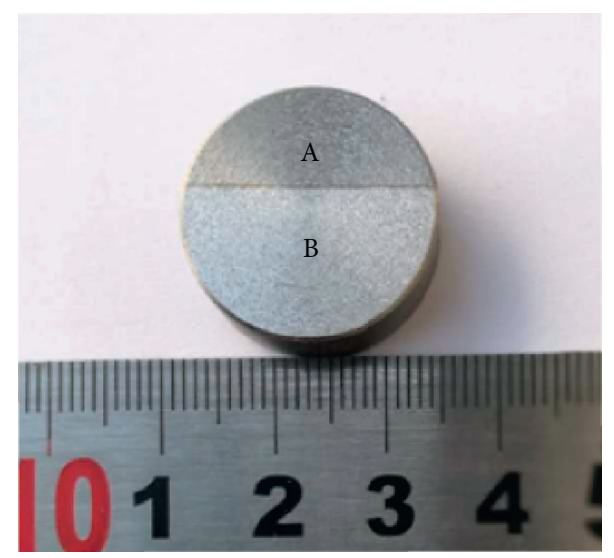

FIGURE 5: Comparison of the appearance of S0. Region A is the surface before cleaning, and region B is the surface after cleaning (200 (W). 


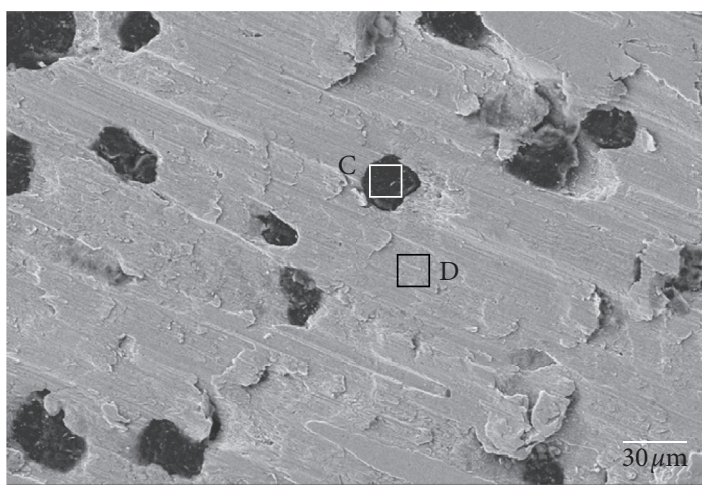

(a)

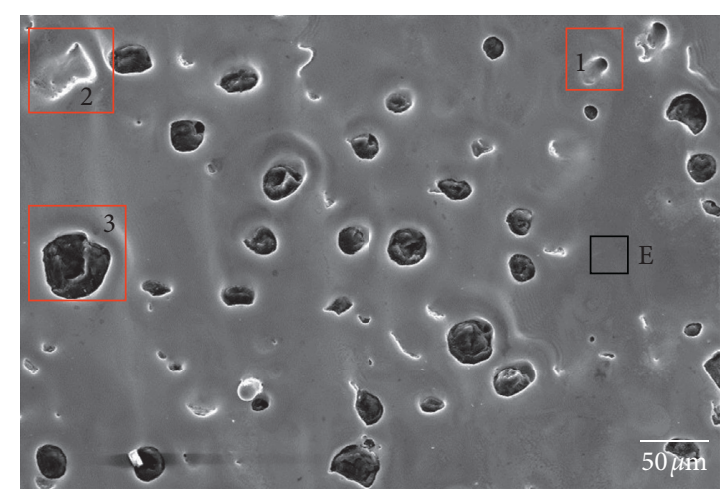

(b)

FiguRE 6: Surface morphologies of initial (a) and $200 \mathrm{~W}$ laser cleaned (b) specimens.

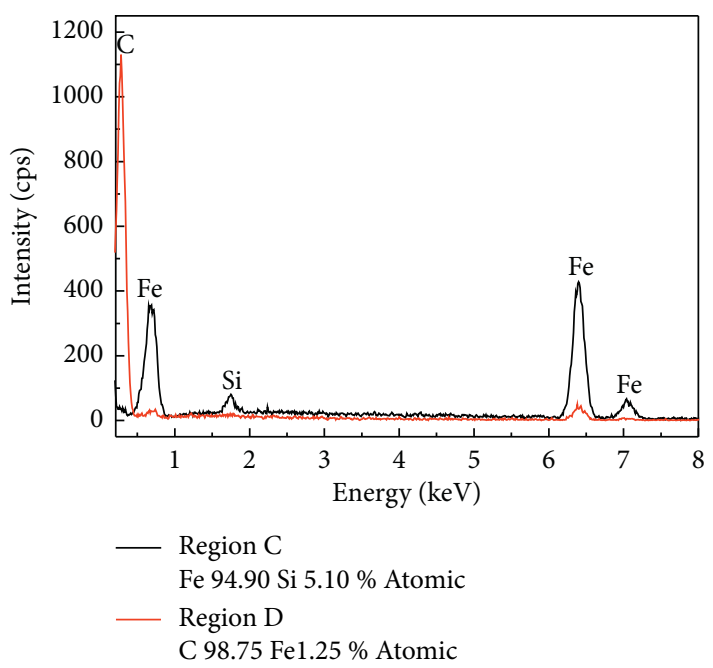

(a)

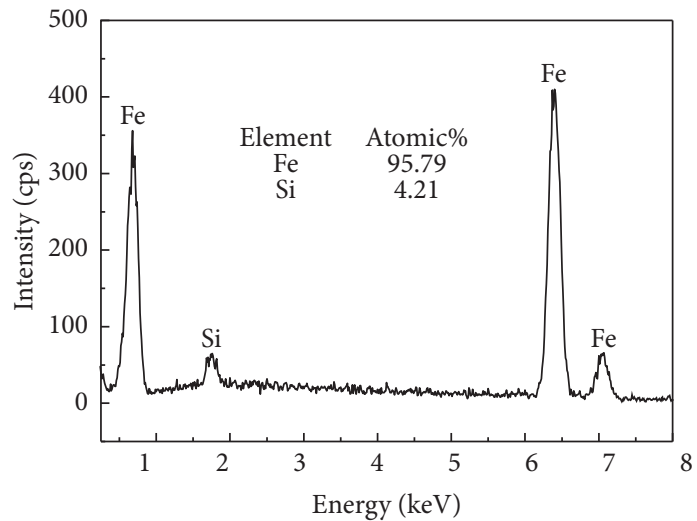

(b)

FIgURE 7: EDS results of regions C and D of initial specimen (a) and region E of the cleaned specimen (b) in Figure 6.

However, deeply embedded graphite particles still exist after laser cleaning. In following experiments, laser cleaning parameters will be optimized to improve the remove efficiency.

Figure 8(a) is the specimen cleaned by using the laser with the power of $340 \mathrm{~W}$ (region F) and $320 \mathrm{~W}$ (region H). Damage is observed on the surface of the specimen cleaned by using the $340 \mathrm{~W}$ laser. SEM/EDS analysis of the circled part of region $\mathrm{F}$ was performed, and its results are shown in Figure $8(\mathrm{~b})$. It can be seen that the atomic ratio of $\mathrm{O}$ is $58.08 \%$, of $\mathrm{O}$ is 58.08 at.\%, demonstrating that oxidation occurred during $340 \mathrm{~W}$ laser cleaning process. The SEM image in Figure 8 (b) reveals that graphite particles were removed but the appearance of the substrate also changed. Some loose materials formed on the surface such as region I could be iron oxide. The appearance of region $\mathrm{H}$ is similar to that of region $B$ in Figure 5. The SEM image of region $\mathrm{H}$ is shown in
Figure $8(\mathrm{c})$. It can be observed that there are still many residual graphite particles. The number of removed particles is more than that of the specimen in Figure 6(b), demonstrating that increasing power intensity to a certain value below damage threshold is a proper way to obtain a better cleaning performance. According to above results, it can be concluded that the safe power intensity for the cleaning of ductile iron substrate is about $320 \mathrm{~W}$, corresponding to $10.86 \mathrm{~J} / \mathrm{cm}^{2}$ $\left(1.086 \times 10^{8} \mathrm{~W} / \mathrm{cm}^{2}\right)$, which is close to the calculated result. According to literatures [10, 23-25], the thick surface layer can be completely removed by increasing cleaning times. Thus, in following experiments, average laser power is adjusted to $320 \mathrm{~W}$ and other parameters are kept the same with prior experiments. The number of laser passes will be increased and tested to improve the cleaning efficiency.

Figure 9(a) is the SEM image of a specimen cleaned 3 times by using the $320 \mathrm{~W}$ laser with $60 \mathrm{~s}$ time gap. 


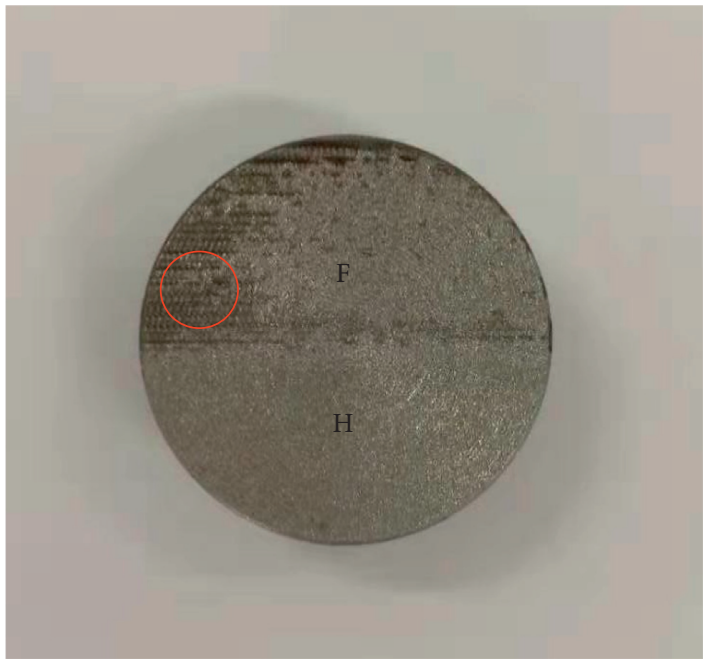

(a)

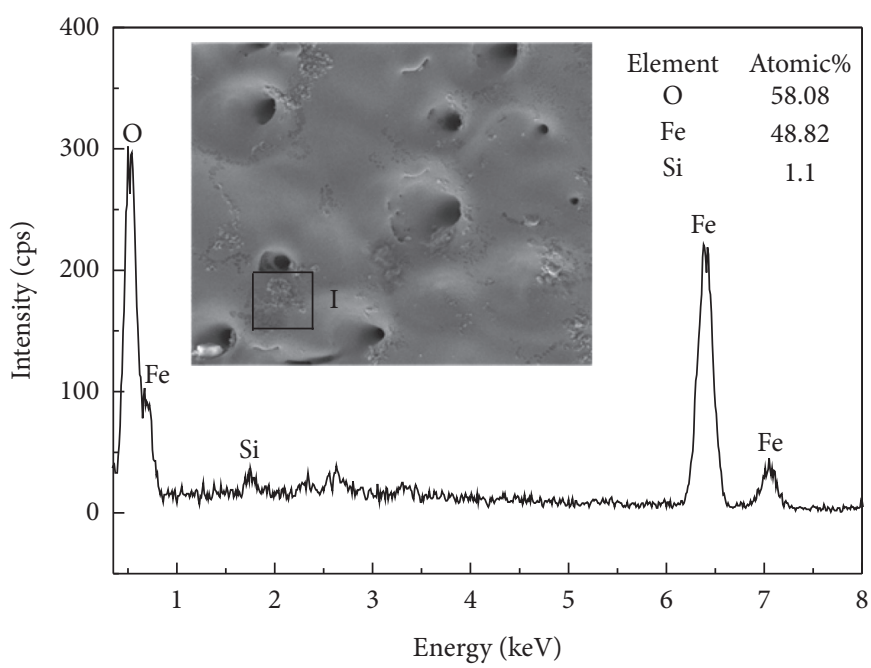

(b)

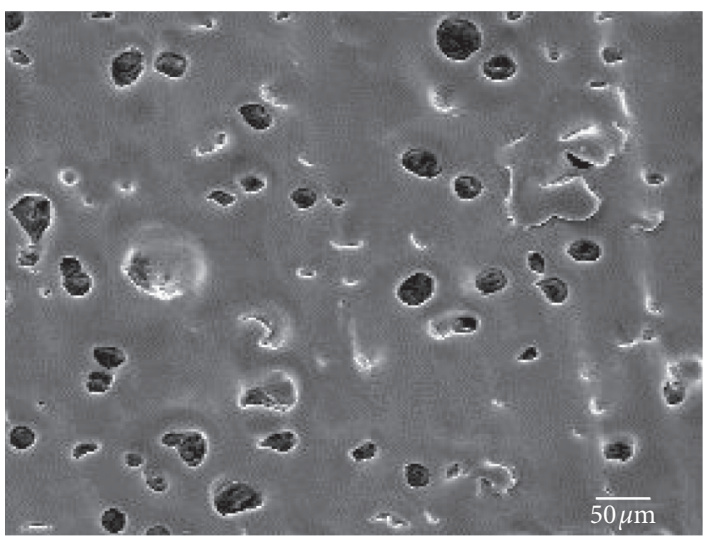

(c)

FIGURE 8: Specimen cleaned by using the laser with power $340 \mathrm{~W}$ (region (F) and $320 \mathrm{~W}$ (region (H) (a); the SEM/EDS analysis of the circled area of region $\mathrm{F}(\mathrm{b})$; the SEM image of region $\mathrm{H}(\mathrm{c})$.

Comparing with Figure $8(\mathrm{c})$, it can be seen that most of graphite particles were removed except those with large diameters or deeply embedded ones. The increasing of cleaning times is a feasible way to obtain an excellent cleaning result. Figure 9(b) shows EDS analysis of the surface after the third pass. The ingredients of substrate (region J) are similar to those of the initial status (Figure 7(a)). However, the ingredients of the graphite area (region K) are different from those of the initial surface (Figure $7(\mathrm{a})$ ), indicating that surface graphite particles were efficiently removed. Oxidation was not observed during laser cleaning process. Therefore, the power intensity of $1.087 \times 10^{8} \mathrm{~W} / \mathrm{cm}^{2}$ is a safe parameter for the cleaning of ductile iron substrate. Time duration more than $60 \mathrm{~s}$ between cleaning passes is necessary. Figure 9(c) shows the SEM image of a specimen cleaned 3 times by using the $320 \mathrm{~W}$ laser but without time gap, which is similar to the image inset in Figure 8(b). Loose materials (e.g., region L) are observed on the surface of ductile iron. It can be concluded that oxidation occurred during laser cleaning process without time gap.

Decreasing the output power is extremely important for the real application of laser cleaning technique, which may save power, shorten the cleaning time, and decrease the oxidation rate during continuous laser cleaning process without time gap. Thus, in following experiment, the output power was decreased to $290 \mathrm{~W}\left(9.85 \times 10^{7} \mathrm{~W} / \mathrm{cm}^{2}\right)$ and cleaning processes were increased to 5 times without time gap between passes. Other experimental parameters were kept the same. The SEM image of the cleaned specimen is shown in Figure 10. Results showed that most of graphite particles were removed, and no region like region L in Figure 9(c) was observed. It can be concluded that more passes should be performed at a lower output power to optimize laser cleaning effect. 


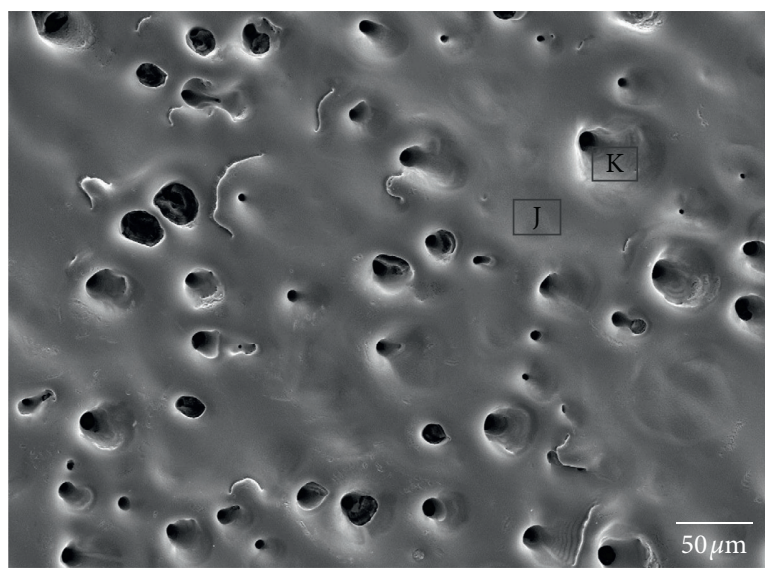

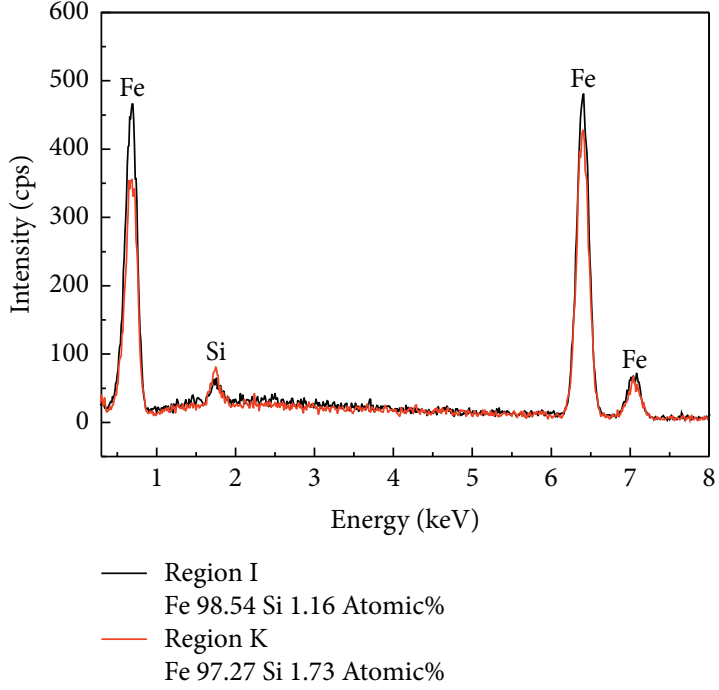

(b)

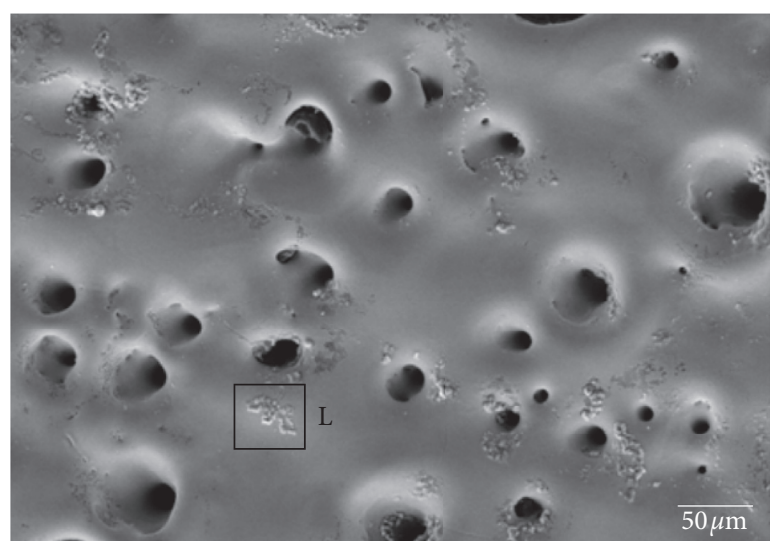

(c)

FIGURE 9: (a) The SEM image of a specimen cleaned 3 times by using the $320 \mathrm{~W}$ laser with $60 \mathrm{~s}$ time gap; (b) EDS analysis of a specimen cleaned 3 times by using the $320 \mathrm{~W}$ laser with $60 \mathrm{~s}$ time gap; (c) the SEM image of a specimen cleaned 3 times by using the $320 \mathrm{~W}$ laser without time gap.

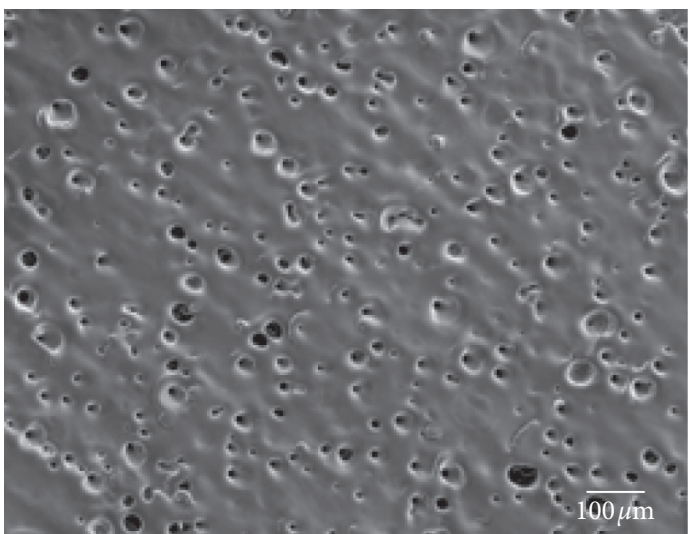

Figure 10: The SEM image of a specimen cleaned 5 times by using the $290 \mathrm{~W}$ laser. 


\section{Conclusions}

In this article, a novel and environmental friendly method is developed to remove graphite particles embedded in the surface of ductile iron to improve its welding performance. Oxidation threshold of laser power intensity of $10 \mathrm{~J} / \mathrm{cm}^{2}$ was obtained by calculation. Graphite particles implanted in the surface of ductile iron were removed effectively by using proposed laser technique. Experimental results showed that oxidation of substrate occurred during laser cleaning process when power intensity of single pulse is higher than $1.087 \times 10^{8} \mathrm{~W} / \mathrm{cm}^{2}$. Most graphite particles were removed after three laser scanning passes with a power intensity of single pulse of $1.087 \times 10^{8} \mathrm{~W} / \mathrm{cm}^{2}$. The time gap between passes is necessary in this case due to the occurrence of oxidation. The optimize power intensity of single pulse is $9.85 \times 10^{7} \mathrm{~W} / \mathrm{cm}^{2}$, and cleaning process is 5 times with continuous laser scanning without time gap. This investigation contributes to the improvement of welding performance of ductile iron.

\section{Data Availability}

The data used to support the findings of this study are included within the article.

\section{Conflicts of Interest}

The authors declare that they have no conflicts of interest regarding the publication of this paper.

\section{Acknowledgments}

This work was supported by the National Natural Science Foundation of China (NSFC) (grant nos. 61705205, 51701087, 51535003, and 2016FBA2004) and Special Foundation for Young Scientists of LFRC (grant no. RCFPD3-2019-3).

\section{References}

[1] Y. Li, S. Dong, S. Yan, X. Liu, P. He, and B. Xu, "Microstructure evolution during laser cladding $\mathrm{Fe}-\mathrm{Cr}$ alloy coatings on ductile cast iron," Optics \& Laser Technology, vol. 108, pp. 255-264, 2018.

[2] V. Dakre, D. R. Peshwe, S. U. Pathak, and A. Likhite, "Effect of austenitization temperature on microstructure and mechanical properties of low-carbon-equivalent carbidic austempered ductile iron," International Journal of Minerals, Metallurgy, and Materials, vol. 25, no. 7, pp. 770-778, 2018.

[3] J. O. Olawale, S. A. Ibitoye, K. M. Oluwasegun, M. D. Shittu, and A. P. I. Popoola, "Forced-air cooling quenching: a novel technique for austempered ductile iron production," International Journal of Metalcasting, vol. 11, no. 3, pp. 568-580, 2017.

[4] M. Polajnar, M. Kalin, I. Thorbjornsson, J. T. Thorgrimsson, N. Valle, and A. Botor-Probierz, "Friction and wear performance of functionally graded ductile iron for brake pads," Wear, vol. 382-383, pp. 85-94, 2017.

[5] M. Gagne, S. Leclerc, S. Helgee, N. Stenbacka, and J. Tani, "The continentalization of science," Modern Casting, vol. 97, pp. 30-34, 2007.
[6] I. Grubova, T. Priamushko, M. Surmeneva et al., "Conference Series," Journal of Physics, vol. 830, Article ID 012109, 2017.

[7] S. M. A. Boutorabi and J. Campbell, "An etching technique for primary austenite dendrites in ductile cast iron," Materials Characterization, vol. 31, no. 3, pp. 127-132, 1993.

[8] M. Grupp in Proceedings of the 16th International Conference Laser Optics, Burbach, Germany, 2014.

[9] Y. Ye, B. Jia, J. Chen et al., "Laser cleaning of the contaminations on the surface of tire mould," International Journal of Modern Physics B, vol. 31, no. 16-19, Article ID 1744100, 2017.

[10] L. Zhu, B. Sun, Z. Li, X. Pan, Y. Chen, and Y. Cao, "The weld quality improvement via laser cleaning pre-treatment for laser butt welding of the HSLA steel plates," Welding in the World, vol. 64, no. 10, pp. 1715-1723, 2020.

[11] C. Zhou, H. Li, G. Chen, G. Wang, and Z. Shan, "Effect of single pulsed picosecond and 100 nanosecond laser cleaning on surface morphology and welding quality of aluminium alloy," Optics \& Laser Technology, vol. 127, Article ID 106197, 2020.

[12] A. P. Kuznetsov, A. S. Alexandrova, O. I. Buzhinsky et al., "Fiber laser cleaning of metal mirror surfaces for optical diagnostic systems of the ITER," Physics of Atomic Nuclei, vol. 78, no. 10, pp. 1155-1163, 2015.

[13] T. Schwarz-Selinger, F. Genoese, C. Hopf, and W. Jacob, "Carbon removal from tile gap structures with oxygen glow discharges," Journal of Nuclear Materials, vol. 390-391, pp. 602-605, 2009.

[14] W. M. Steen and J. Mazumder, Laser Material Processing, Springer, London. UK, 2010.

[15] Z. Zhang, J. Zhang, Y. Wang et al., "Optical humidity detection based on tunable diode laser absorption spectroscopy," in Proceedings of the Second International Conference on Photonics and Optical Engineering, p. 116114, Aveiro, Portugal, February 2017.

[16] G. Zhang, X. Hua, Y. Huang et al., "A promising material for microwave absorption," Applied Surface Science, vol. 359, pp. 1-9, 2019.

[17] B. Rauh, S. Kreling, M. Kolb et al., "UV-laser cleaning and surface characterization of an aerospace carbon fibre reinforced polymer," International Journal of Adhesion and Adhesives, vol. 82, pp. 50-59, 2018.

[18] Q. H. Tang, D. Zhou, Y. L. Wang, and G. F. Liu, "Laser cleaning of sulfide scale on compressor impeller blade," Applied Surface Science, vol. 355, pp. 334-340, 2015.

[19] R. Li, J. Yue, X. Shao, C. Wang, F. Yan, and X. Hu, “A study of thick plate ultra-narrow-gap multi-pass multi-layer laser welding technology combined with laser cleaning," The International Journal of Advanced Manufacturing Technology, vol. 81, no. 1-4, pp. 113-127, 2015.

[20] S. Arif, S. Bushuk, A. Kouzmouk, H. Tatur, S. Batishche, and W. Kautek, "Middle-ultraviolet laser cleaning of particulates from sized ground wood cellulose and pure cellulose paper," Journal of Cultural Heritage, vol. 15, no. 6, pp. 602-608, 2014.

[21] A. Kumar and D. J. Biswas, "Particulate size and shape effects in laser cleaning of heavy metal oxide loose contamination off clad surface," Optics \& Laser Technology, vol. 106, pp. 286-293, 2018.

[22] X. Li, T. Huang, A. W. Chong, R. Zhou, and Y. S. Choo, "Target Setting in Tournaments: Theory and Evidence from China," Opto-Electronic Engineering, vol. 44, pp. 341-344, 2017.

[23] C. Zhou, H. Li, G. Chen, G. Wang, and Z. Shan, "Effect of single pulsed picosecond and 100 nanosecond laser cleaning 
on surface morphology and welding quality of aluminium alloy," Optics \& Laser Technology, vol. 127, pp. 1-9, 2020.

[24] D. S. Prokuratov et al., "Laser cleaning of archaeologically corroded iron objects with inlays," Optical and Quantum Electronics, vol. 52, pp. 13-125, 2020.

[25] J.-E. Kim, M.-S. Han, and J.-D. Kim, "Removal characteristics of shop-primer paint by laser energy density in Q-switching fiber laser cleaning," Modern Physics Letters B, vol. 34, no. 07n09, p. 2040042, 2020. 